\title{
Analysis and prediction of brittle failure in rock blocks having a circular tunnel under uniaxial compression using acoustic Emission technique: laboratory testing and numerical simulation
}

\author{
Ratan Das $^{1 *}$ (D, Ranbir Dhounchak ${ }^{2}$ and T. N. Singh ${ }^{3}$
}

\section{${ }^{*}$ Correspondence:}

ratandasdjn91@gmail.com;

ratandas@iitkgp.ac.in

${ }^{1}$ Department of Geology \&

Geophysics, Indian Institute

of Technology Kharagpur,

Kharagpur 721302, West

Bengal, India

Full list of author information

is available at the end of the article

\begin{abstract}
In this research, the failure mechanism and anomalous behavior of intact and jointed rock block having a circular tunnel under compression are studied. This was done by monitoring the progressive failure of a rock tunnel subjected to uniaxial loading. The tests were conducted in sandstone blocks and "Acoustic Emission" (AE) technique was used to identify the crack damage and other failure attributes. Three cases have been considered in the research, i.e. tunnel in the intact rock, with horizontal joints, and with vertical joint sets. Images of progressive failure, acoustic signals, and applied loads were simultaneously recorded during the test. The intact block demonstrates continuous crack generation while the block with horizontal joint set shows a stepwise cracking pattern. In the third case where the vertical joints were employed, the deformation was largely roof failure and joint perpendicular extension was dominant. The AE events show that a sudden drop and then a quiet period of seismic "Ib value" could be considered as the precursors to forecast the rockburst hazard. The paper also compares the results of the physical model test with a 2D finite element model. The compared results show good agreement between the physical and numerical models.
\end{abstract}

Keywords: Tunnel Deformation, Acoustic Emission, Failure Pattern, Joints

\section{Introduction}

The study of jointed rockmass failure under a compressional environment is a widespread and interesting subject among engineering geologists. Especially, in underground construction, having knowledge of the rock deformation process and its failure mechanism is very crucial for long-term stability as they govern the overall kinematical and mechanical behavior of the rockmass [1]. When an opening is created in a rock, the surrounding rocks around the opening release appreciable pressure causing an explosion, as it attempts to re-establish stress and strain equilibrium [2, 3]. Joints, if present, are the chief influencing feature for the deformation, and instability

(c) The Author(s) 2021. This article is licensed under a Creative Commons Attribution 40 International License, which permits use, sharing adaptation, distribution and reproduction in any medium or format, as long as you give appropriate credit to the original author(s) and the source, provide a link to the Creative Commons licence, and indicate if changes were made. The images or other third party material in this article are included in the article's Creative Commons licence, unless indicated otherwise in a credit line to the material. If material is not included in the article's Creative Commons licence and your intended use is not permitted by statutory regulation or exceeds the permitted use, you will need to obtain permission directly from the copyright holder. To view a copy of this licence, visit http://creativeco mmons.org/licenses/by/4.0/. 
of surrounding rocks. The failure in the jointed rockmass generally occurr due to the shearing of discontinuities. The shear behavior of joint depends on some key factors such as length of joint, joint roughness, joint stiffness, stiffness of the surrounding rock, joint condition, joint infillings, shear rate, etc. [4-6]. Therefore, the study of deformation and failure mechanisms of joints is primarily important in the course of stability analysis of tunnels.

The effects of joint on the stability of tunnels have been appreciated by mechanical analysis, numerical simulation $[7,8]$, and physical modelling technique $[9,10]$. Jia and Tang $[8]$ numerically investigated the influence of joint dip and the lateral pressure coefficient on the stability of tunnel in a jointed rock mass and reported different failure modes in tunnels. Wang and Huang [7] also reported that joint sliding failure and shear deformation is mainly responsible for the joint-induced anisotropic deformation surrounding a tunnel. Moyo and Stacey [9] have developed a small scale 2D jointed rockmass tunnel physical model to observe the tunnel boundary deformation process. They reported that, in highly jointed rockmass, there is a significant movement across the joints. However, universally accepted concepts have not been achieved either in theory or in practice in terms of deformation and failure of the tunnels in the jointed rock mass.

The jointed rockmass manifests complex mechanical behavior like anisotropy, dilatancy, hysteresis, irreversible strain, and strongly path-dependent stress-strain relationships which is generally associated with the existence of a lot of joints or cracks and their propagation [11]. The joint orientation also play an important role in creating voids and occurrence of permanent deformations. The deformational behavior becomes highly anisotropic and a very high lateral strain may be exhibited by the rockmass under uniaxial loading if the joints are critically oriented. This kind of deformational behavior in jointed rockmass is unpredictable but for many reasons, it is important to predict the time, location, and intensity of potential rockburst. Rock fracture and rockburst in stressed rock have been observed in the laboratory by many methods like SEM, microscopy, optical camera, far-infrared (FIR) techniques, etc. These techniques provide a direct and visual description of the fracturing process in a straightforward way.

Sellers and Klerck [12], first perform a series of physical and numerical model tests to investigate the behavior of the rock surrounding a circular tunnel under high confining pressures. They have used Norite and Elsburg quartzite rock blocks made from series of rock plates to simulated the presence of horizontal bedding planes. Their physical model tests as well as numerical simulation results confirmed that the presence of discontinuities can alter the fracture patterns associated with excavation. The discontinuities induce more fracturing than is observed in the solid blocks.

Liang et al. [2] studied the anomalous behaviors of a circular tunnel in intact granitic rock to monitor the progressive failure before rockburst using the acoustic emission (AE) and far-infrared (FIR) technique. They derived the b-value from the amplitude distribution data of AE to predict the tunnel rockburst. Their results showed that the vertical stress enhanced the stability of the tunnel, and the tunnels with higher confining pressure demonstrated more abrupt and strong rockburst.

In the past few years, many methods of estimating rock bursts have been proposed, including rock mechanics assessment, stress detection, and modern mathematical theories. However, a comprehensive understanding of rock bursts and associated damage 
mechanisms have remained elusive till now [2, 13, 14]. Many researchers indicated that the parting induces additional fractures that are completely different from the classical breakout patterns, being captured within the layers that intersect the tunnel [12, 15].

This research aims to analyze the shape and type of failure around the tunnel, influence by the regularly spaced joint planes through a series of physical model experiments. Three cases have been analyzed in the tunnel physical model i.e. tunnel in the intact rock, tunnel with horizontal joint set, and with the vertical joint set. The behavior of the crack damage and fracturing processes in rock blocks under vertical loading is studied with the help of $\mathrm{AE}$ and results were compared with finite element simulation results.

\section{Methodology}

\section{Specimen preparation}

The sandstone block sample used in this study is collected from the Jodhpur district of Rajasthan, India (Fig. 1). This sandstone ranges from coarse to medium-grained that shows a smoothing texture and charming light red color due to iron content in the sample. It contains 96.6\% quartz and relatively small proportions of feldspar (1.2\%) with other minor minerals, hence there is very less inhomogeneity as compared to other polymineralic crystalline rocks.

The dimension of the sample specimen was approximately $150 \mathrm{~mm}$ (Width) $\times 150 \mathrm{~mm}$ (Height) $\times 80 \mathrm{~mm}$ (Depth). Three conditions were tested in this study, viz tunnel in the intact sandstone rock, with horizontal joint set, and with the vertical joint set. To model a jointed rockmass, the rock blocks were cut and sliced of about $15 \mathrm{~mm}$ by Rock Cutting Machine (Fig. 2). The rock pieces then glued together using an epoxy type ceramic substrate adhesive to represent the jointed tunnel model. As suggested by Roy et al. [17] the adhesive was chosen such that the analogous joint behaves similarly to the actual rock joints. In the prepared jointed block, a $30 \mathrm{~mm}$ diameter hole is drilled through the center of the specimens. The physical and mechanical properties of the intact sandstone were determined in the laboratory as per the ASTM/ISRM standards [18-21] which are tabulated in Table 1.

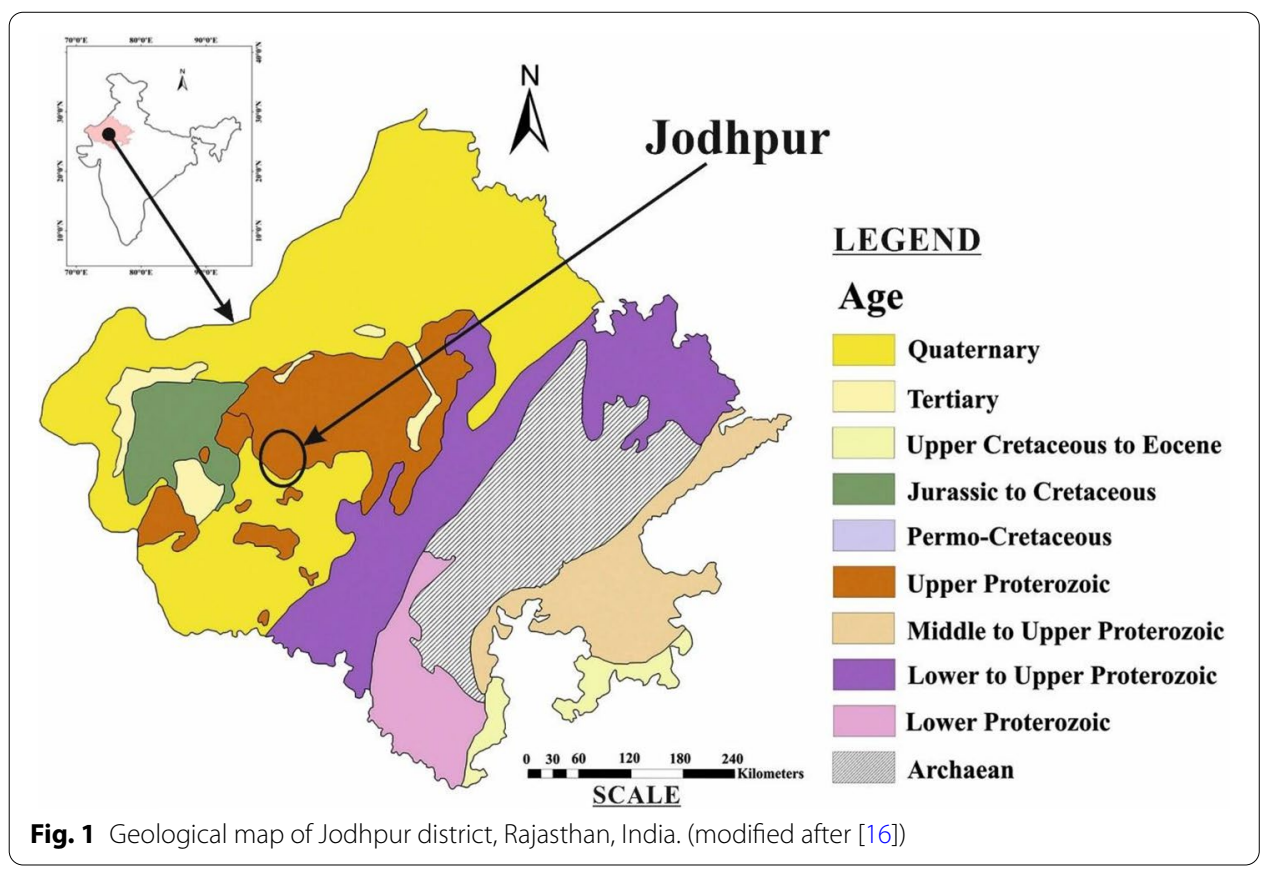




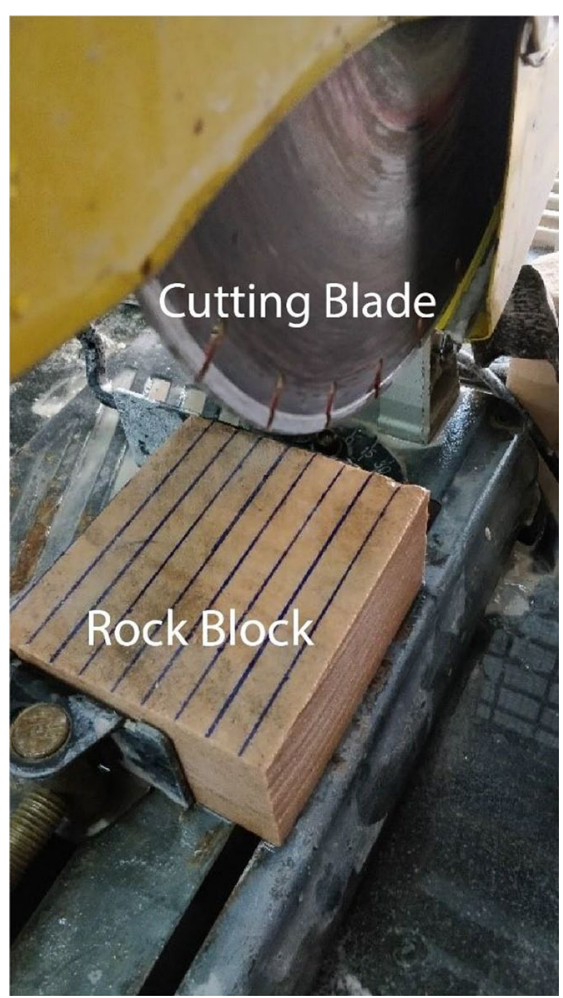

Fig. 2 Rock cut into slices

Table 1 Intact rock properties

\begin{tabular}{lllllll}
\hline $\begin{array}{l}\text { Density, }(\rho) \\
\left(\mathrm{Kg} / \mathrm{m}^{3}\right)\end{array}$ & $\begin{array}{l}\mathrm{UCS},\left(\sigma_{\mathrm{c}}\right) \\
(\mathrm{MPa})\end{array}$ & $\begin{array}{l}\text { Tensile } \\
\text { Strength, }\left(\sigma_{\mathrm{t}}\right) \\
(\mathrm{MPa})\end{array}$ & $\begin{array}{l}\text { Elastic } \\
\text { Modulus, E } \\
(\mathrm{GPa})\end{array}$ & $\begin{array}{l}\text { Poisson's } \\
\text { ratio, }(\mathrm{v})\end{array}$ & $\begin{array}{l}\text { Cohesion, }(\mathrm{c}) \\
(\mathrm{MPa})\end{array}$ & $\begin{array}{l}\text { Friction Angle, } \\
(\varphi)\left(^{\circ}\right)\end{array}$ \\
\hline 2291 & 34.98 & 7.89 & 20.24 & 0.22 & 8.30 & 39 \\
\hline
\end{tabular}

The deformation of joints dominates the elastic deflection of the intact rock at relatively low-stress levels which are generally encountered in near-surface excavations. But at higher stress levels, the slippage and closure of joints constitute the major part of a settlement in rock [22]. Joint deformability can be described by the character of the stress-deformation curves. Goodman et al. [23] introduced the terms "Normal Stiffness" $\left(K_{n}\right)$ and "Shear Stiffness" $\left(K_{s}\right)$ to describe the following equations:

$$
\begin{gathered}
K_{n}=\frac{\sigma_{n}}{V_{j}} \\
K_{s}=\frac{\tau}{d_{h}}
\end{gathered}
$$

where,

$\sigma_{n}=$ Normal stress, $V_{j}=$ Normal displacements, $\tau=$ shear stress, $d_{h}=$ shear displacements.

The properties of the rock joints were obtained from direct shear and normal load tests carried out on joints as suggested by Prudencio and Van Sint Jan [24]. As per the tests, 
the value of the joint normal stiffness $\left(K_{n}\right)$ varied between 33,089 and $39,553 \mathrm{MPa} / \mathrm{m}$. Direct shear tests on the laboratory gave a value for the joint shear stiffness $\left(K_{s}\right)$ of between 13,424 and $14,585 \mathrm{MPa} / \mathrm{m}$. For the numerical simulation, the average value of $36,404 \mathrm{MPa} / \mathrm{m}$ and $13,882 \mathrm{MPa} / \mathrm{m}$ was used as Normal and shear stiffness respectively.

\section{Loading condition}

Uniaxial loading is applied to the specimens to model the tunnel under the vertical compressional condition and the deformation concerning the applied vertical force was monitored continuously. The Universal Testing Machine (UTM) used in this study was displacement controlled. The displacement rate was set to $0.2 \mathrm{~mm} /$ minute. To nullify the boundary effects, the side length of the specimens was kept 5 times that of the diameter of the tunnel [25-27]. A high-resolution video recorder was stationed in front of the testing machine to record the progressive failure of the sandstone blocks during the test (Fig. 3).

\section{Acoustic emission system}

The word "Acoustic" is originated from the Greek word "akoustikos" which means "hearing". For many centuries, the precursors to any kind of structural failure have been sounds that are released before the failure of supporting materials or members. AE testing is recognized as a very powerful non-destructive tool (NDT) used to examine the behavior of materials which is deforming under stress [28]. The phenomenon of AE is defined as the propagation of elastic waves due to the release of localized internal energy, such as a micro-fracture in elastic material $[29,30]$.

Discontinuities in rock release energy as the rock is exposed to mechanical loading. This energy travels in the form of high-frequency stress waves. These waves are received by the sensors that convert the energy into voltage. This voltage is then electronically amplified and the use of timing circuits is further processed as AE signal data. Analysis of the collected data comprises the characterization of the received voltage signals according to their source location, voltage intensity, and frequency content.

In this present study, the $\mathrm{AE}$ activities were recorded by two piezoelectric transducers from Physical Acoustics Corporation (MISTRAS). The sensor type is PAC R6D. The

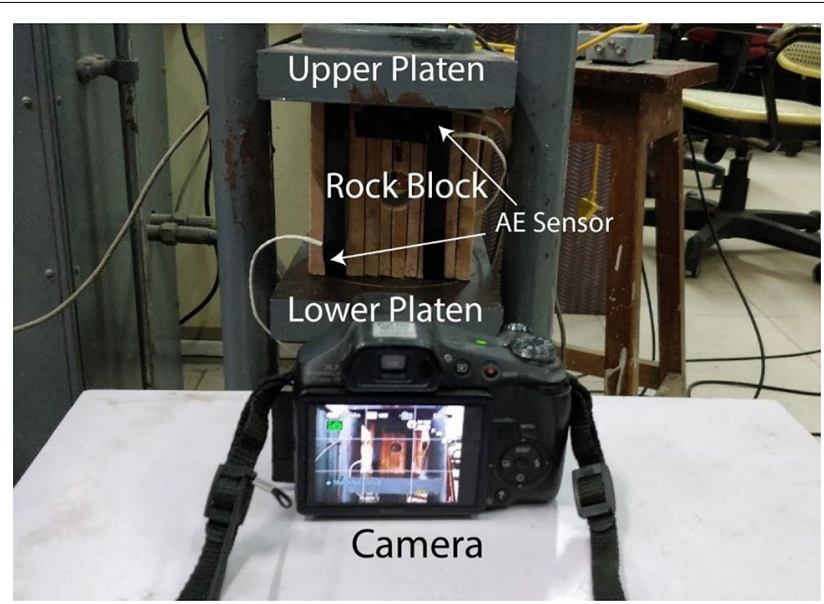

Fig. 3 Continuous video recording with a high-resolution camera 
AE sensors calibration methodology is based on ASTM E1106-12 (Reapproved 2017) [31] and ASTM E1781/E1781M-13 [32] standards. This two-piezoelectric AE sensor was mounted on the sample, and the AE signals were logged simultaneously with the applied load. The transducers were connected through a $40-\mathrm{dB}$ pre-amplifier to the $60-\mathrm{dB}$ front amplifier with a voltage gain of $28 \mathrm{~W}$. A voltage preamplifier amplifies the voltage output from the sensor. The acoustic signals were filtered in the frequency range from $30 \mathrm{kHz}$ to $3 \mathrm{MHz}$. The signal threshold of the system was set to $45 \mathrm{~dB}$. The maximum signal amplitude was $100 \mathrm{~dB}$ and the maximum sample rate was 1 million samples/second. The multiparameter $\mathrm{AE}$ data, including $\mathrm{AE}$ hits, $\mathrm{AE}$ counts, amplitudes, and $\mathrm{AE}$ energy (in Joules) was obtained using a computer-based AE system.

In $\mathrm{AE}$, different types of cracks generate different types of $\mathrm{AE}$ signals which is related to the frequency and amplitude of the AE signals. One approach being used to evaluate crack damage in a material is the use of b-value of AE signal [33]. The seismib b value is also known as amplitude-frequency distribution analysis. The amplitude data of that linear range is used to compute the b-value following the Gutenberg-Richter relationship (GBR) for the cumulative frequency distribution data [34]. Gutenberg-Richter has defined the relationship between magnitude and frequency as below:

$$
\log [N(M)]=a-b M
$$

In terms of $\mathrm{AE}$ technique, the $\mathrm{AE}$ amplitude is divided by a factor of 20 , is the number of $\mathrm{AE}$ hits with an amplitude greater than the threshold, and is an empirical constant [35].

$$
\log [N(M)]=a-b\left[\frac{A_{d b}}{20}\right]
$$

where,

$N(M)=$ The number of events with magnitude larger than $M$.

$A_{d b}=$ Peak amplitude of the AE events (dB).

$a$ and $b=$ Two constant coefficients.

The parameter $b$ measures the relative numbers of small and large earthquakes. The b-value is a well-known macro and micro-structural crack identification method. It is defined as the negative gradient of the log-linear plot of earthquake frequency magnitude [29]. The micro-cracks generate a large number of weak $\mathrm{AE}$, which leads to a relatively high $b$ value, while macro-cracking leads to relatively low $b$ values since they generate a large number of strong AE signals. Hence, a sharply decreasing b value can often be used as an indicator of near-peak stress. According to Smith [36], the value of " $b$ " is usually calculated by the following method

$$
b=\frac{\log _{10} e}{\bar{M}-M_{o}}
$$

where,

$\bar{M}=$ mean magnitude of the sample, and

$M_{o}=$ minimum magnitude considered.

However, larger b-values represent the stage of micro-crack occurrence and vice versa. The application of $b$ value in engineering material will be problematic since it originates 
from seismology [37]. Hence, the improved b-value $(I b)$ is introduced and stated used in engineering materials and given in the equation below

$$
I b=\frac{\log _{10} N\left(\mu-\alpha_{1} \sigma\right)-\log _{10} N\left(\mu+\alpha_{2} \sigma\right)}{\left(\alpha_{1}+\alpha_{2}\right) \sigma}
$$

where,

$N=$ number of events with magnitude larger than $\mathrm{M}$,

$\mu=$ mean amplitude,

$\sigma=$ standard deviation, and

$\alpha_{1}$ and $\alpha_{2}=$ user-defined constants which would represent coefficients of lower and upper limits of the amplitude range to yield a proper straight line [29].

\section{Results and discussion}

\section{AE characteristics in different conditions}

As mentioned by Tian et al. [38], the failure process during rock loading is an energy conversion process of absorbing and releasing phenomena. From AE energy viewpoint,
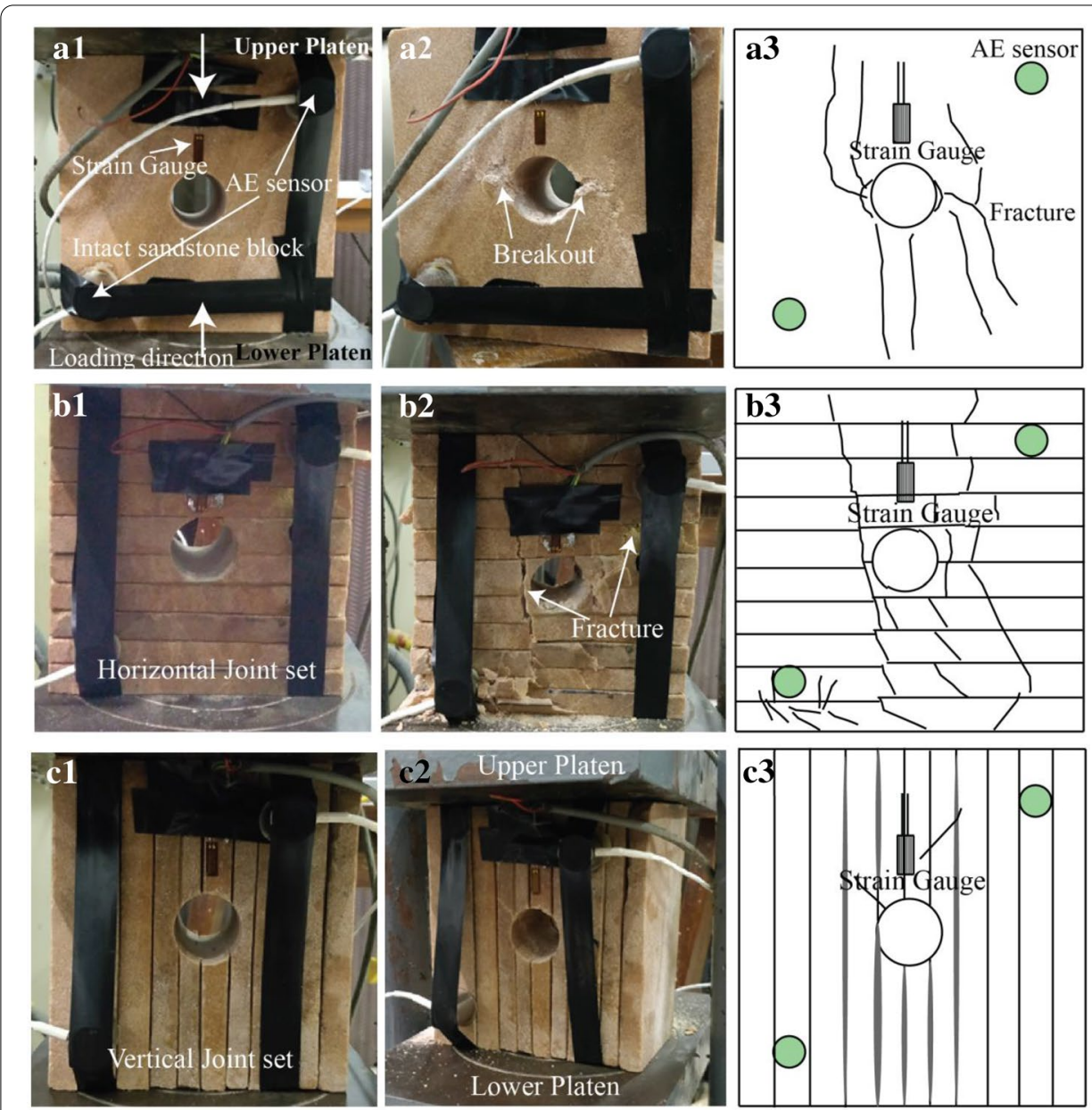

Fig. 4 Representative photos of cracking damages of the rock blocks with illustrations for all three cases i.e. intact rock block (a1, a2, and a3), block with horizontal joint set (b1, b2 and b3) and block with vertical joint set (c1, c2 , and c3) 
the variation characteristics during the process of rockburst tests are more distinctive. Figure 4 demonstrates the crack damage of the rock blocks for all three cases.

\section{Intact block}

During the early loading stage ( $0-35 \%$ of the maximum load), the opening was stable. As the loading continued, the classical failure pattern of primary cracking started which results in the ejection of the small sand particles within the hole. Cut through cracks are also visible on both sides of the tunnel periphery after the violent ejection of rock pieces. The AE data and load vs time graph for the intact rock is plotted in Fig. 5a. The video footage revealed that the spalling initiated at the tunnel sidewalls when the vertical stress was about 0.55 times the failure load of the intact rock block specimen. The cumulative count (CC) drastically increases at about 200s (Fig. 5b). These cracks are formed due to the linking up of micro-cracks resulting from stress concentration higher than the failure load around the hole creating grain boundary and intergranular cracks. The crack tip moves towards each other and the local stress field caused the tip to repel each other. This finally creates crack growth and crack overlapping. At the last stage, all the small micro-cracks are linked up and form a larger macro crack. As the load approaches peak value, forceful ejection of sand particles from the sidewall and exfoliation accompanied by the ringing sound of the burst (Fig. 4(a2) and Fig. 6(a-f)). The peak energy release occurs at $470 \mathrm{kN}$. At that point, the spalling a distance of about $9 \mathrm{~mm}$ outside the original radius of the circular hole.

A complete failure pattern with cracks formed around the circular hole in the intact block is illustrated in Fig. 4(a3). Most of the cracks are continuous or having high persistency. The intact block test was repeated and the complete failure steps can be seen in Fig. $6(\mathrm{a}-\mathrm{f})$.

\section{Horizontally jointed block}

For the horizontally jointed model, cracks first occur near the roof of the tunnel and tried to extend in both upward and downward directions. The AE data and load vs time graph for the intact rock is plotted in Fig. 7a. The horizontally layered slices above the tunnel crown acting more or less like a beam structure. As the load increases, fracture extends upward. At the same time, fracture also generated near the side walls extending from top to bottom on both sides (Fig. 4(b1, b2 and b3) and Fig. 8(a-e)).

The horizontal joints have a significant effect on the crack formation and fracture pattern, which is completely different from the intact block case. Here, the cracks have a stepwise appearance, unlike the intact block case where the cracks were more or less continuous. As the loading continued, the breaking on the tunnel wall is not much prominent.

The kinetic energy release is the numerical equivalent measure of AE. The $\mathrm{CC}$ increases with the increase in loading, as shown in Fig. 7b, and there is an interval (200-250 s) in which the slope of the CC curve is low indicating the macrocrack formation process (see Fig. 8c). The first stage of high energy release was occurred during the early stage of loading or at lower stress levels which continues over a wide range of applied load. The second maximum energy release occurred near the failure 


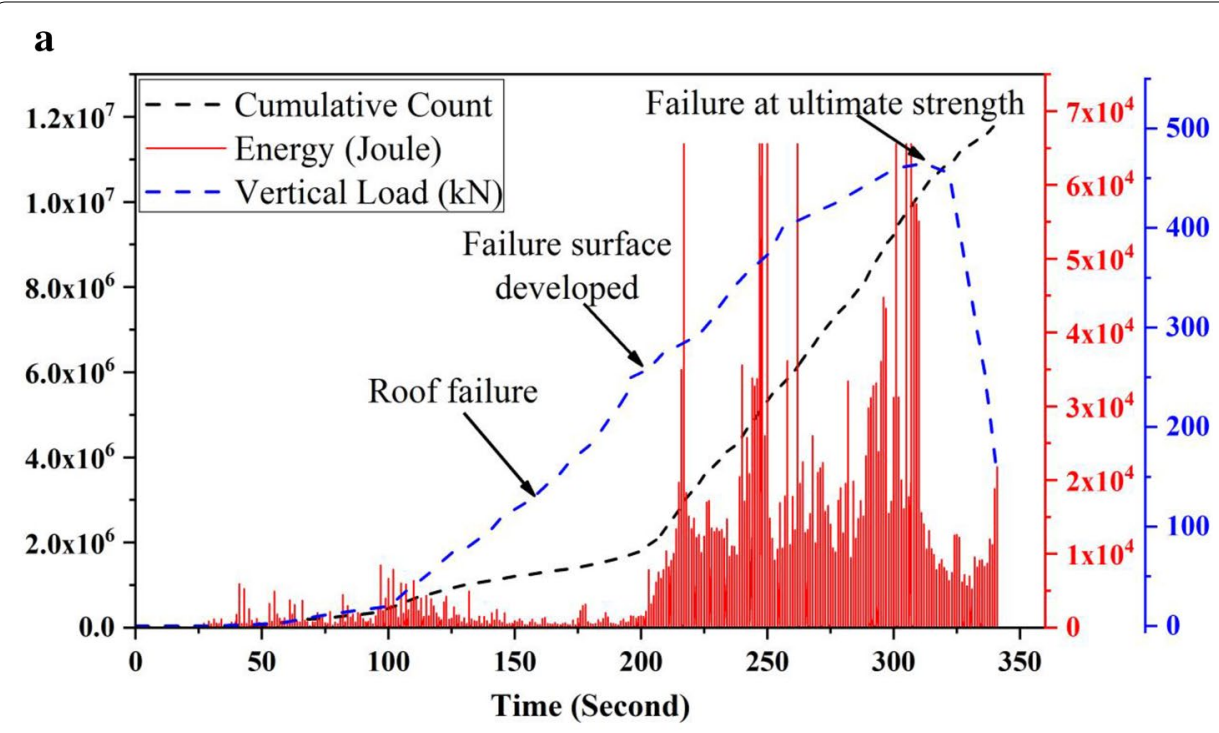

b

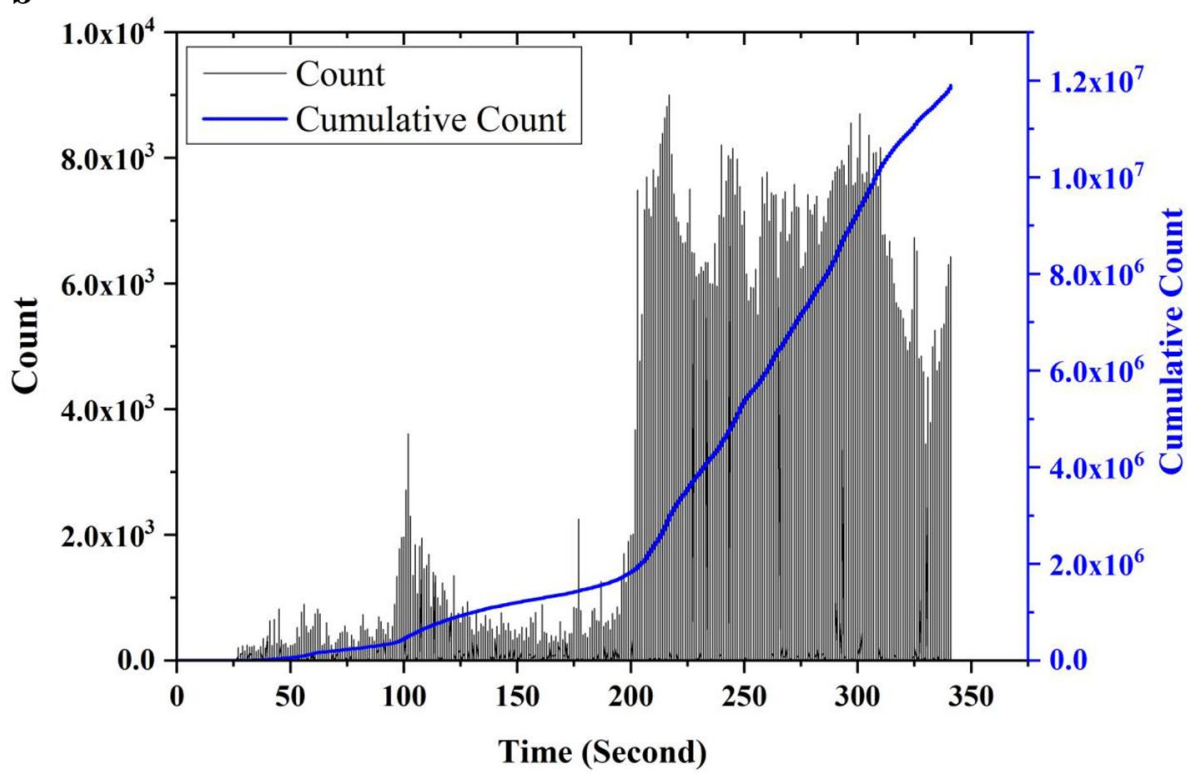

Fig. 5 For Intact rock, (a) Plot showing the acoustic behavior and load vs time (b) Count and cumulative count vs Time

load. Relatively fewer energy peaks were recorded as the loading approaches peak value, indicating massive energy accumulation before failure. At the failure stage, the damage along and across the hole is visible in Fig. 4b2 \& Fig. 8e. The horizontal rock slices dominantly failed in layered beam mode and a large shear crack is also observed along the length of the hole. This test was repeated and the failure patterns can be seen in Fig. 8(a-e). 

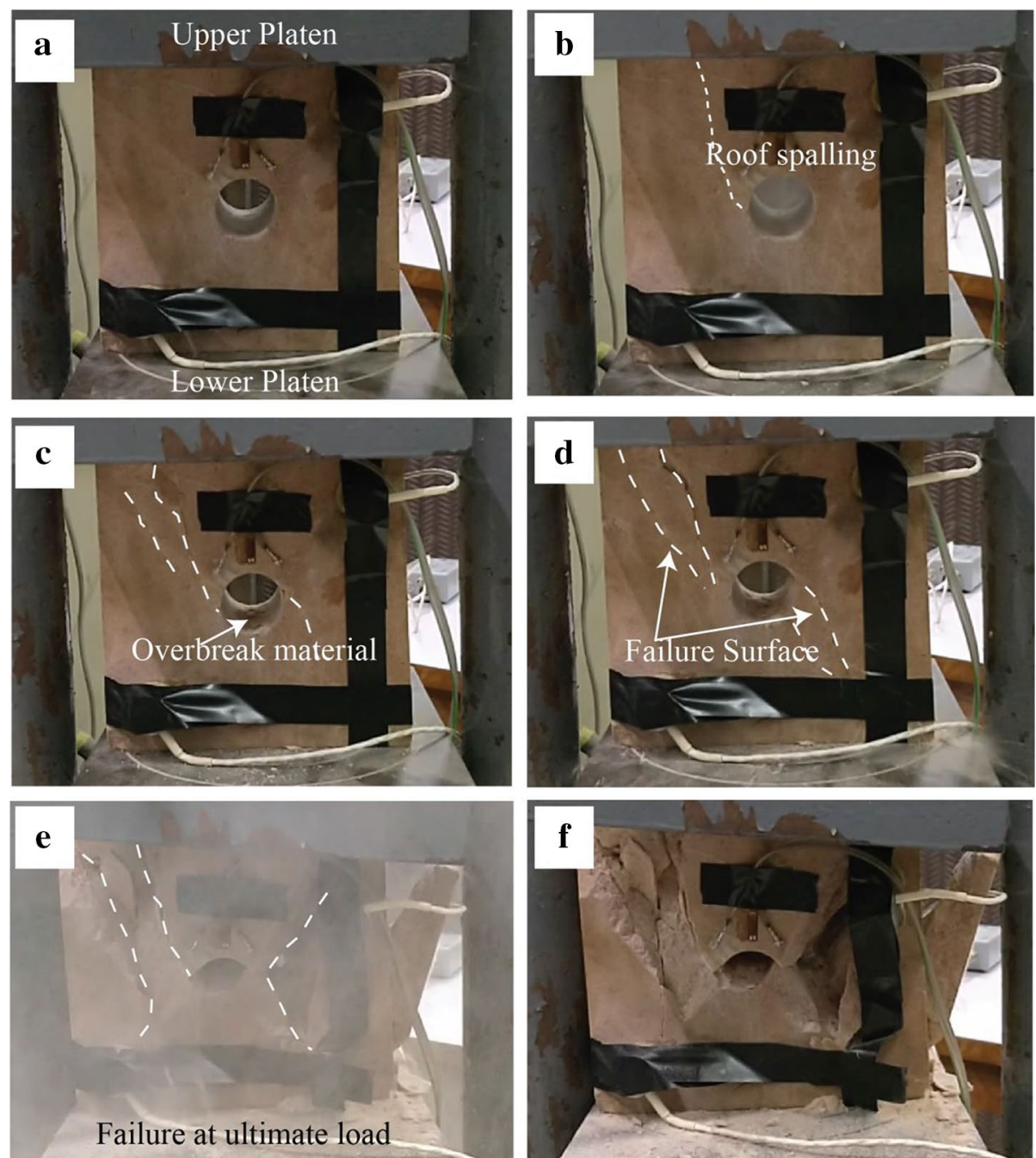

Fig. 6 Failure in intact sandstone block with a circular opening, as the load is applied following failure pattern results starting from (a-f). a Initial equilibrium, no-load acting on the block, (b) Between 20-25\% of the failure load, spalling occurs from the tunnel roof and a crack development is started on the left wall, (c, d) overbreak is visible and on both the sidewall crack is starting propagating, $(\mathbf{e}, \mathbf{f})$ the block is failed at its ultimate strength

\section{Vertically jointed block}

In this case, the dip of the joint in the rock block was $90^{\circ}$. During the experiment, as the load increases in the vertical direction, the joint open up normal to the joint set due to resultant tension in the horizontal direction, which is a very common engineering phenomenon.

During the initial loading stage, there is an initiation and propagation of newly formed micro-cracks which increases the AE counts (see Fig. 9a). After an increase up to a certain peak, it underwent a downward period even though the vertical load was increasing. The vertical block above the tunnel crown is moved into the tunnel which is solely supported by its own joint shear strength. The CC vs time shown in Fig. 9b. A relatively small number of AE data recorded at the final decreasing stage. 


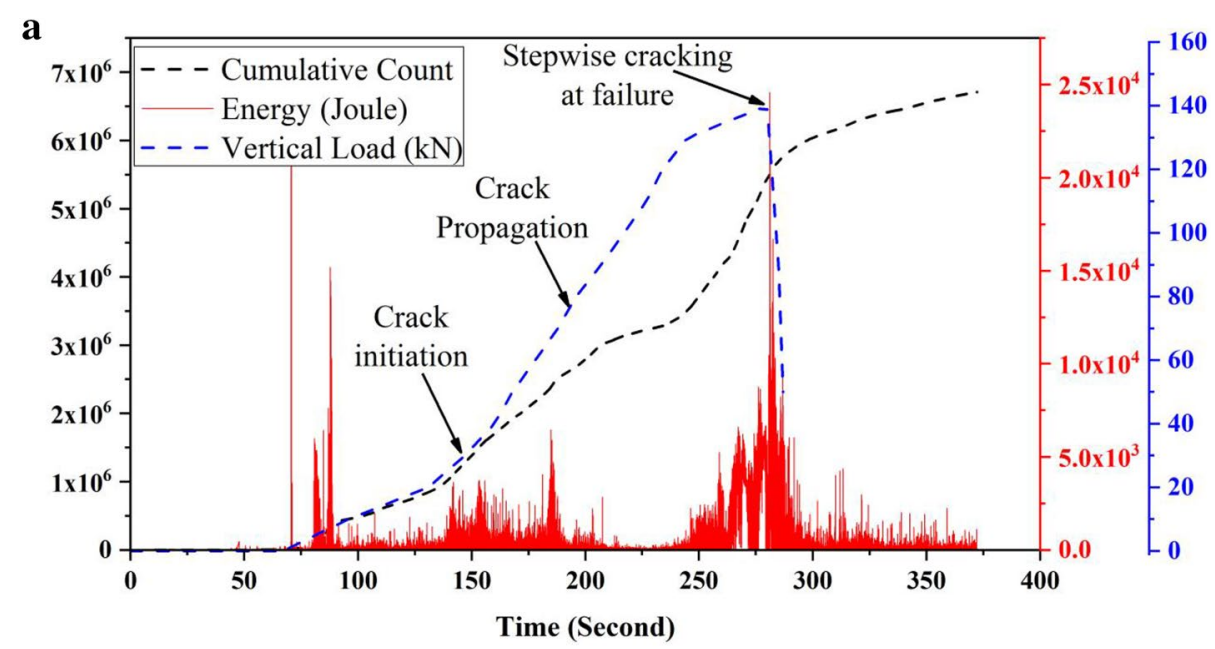

b

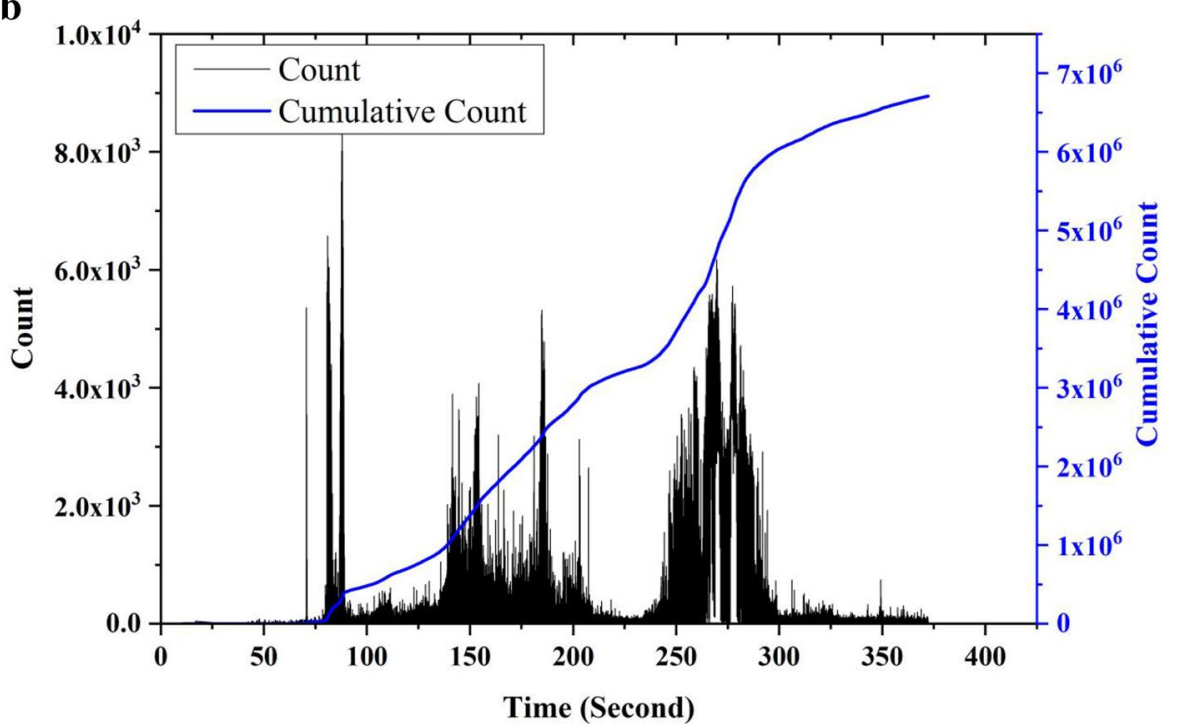

Fig. 7 Horizontally jointed model, a Plot showing the acoustic behavior and load vs time (b) Count and cumulative count vs Time

At the failure stage, the weakened sandstone opening could not able to sustain such a great amount of applied load $(195 \mathrm{kN})$ and the potential energy is released by the surrounding rock to attain a new equilibrium stage which is followed by a sharp vertical load drop.

The joint parallel extension was observed during the failure (Fig. 4 (c1, c2, and c3)). Since the failure is brittle, a large number of $\mathrm{AE}$ of varying amplitude is observed due to the formation of micro shear cracks. There is no inner wall deformation detected because the propagation of crack from the circular hole in case of vertical joints is absent. The existence of vertical joint acts as a barrier for the stress concentration, 

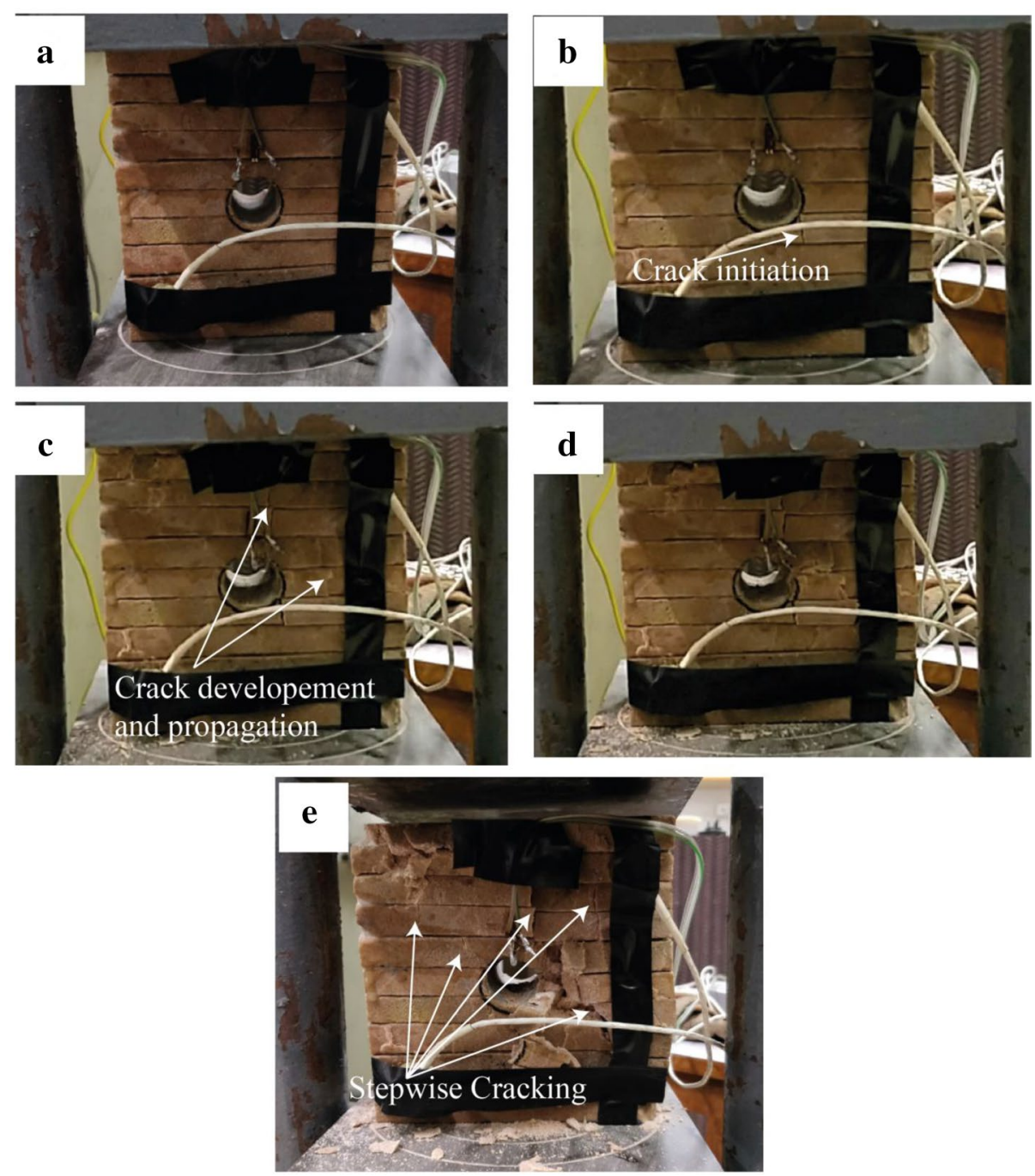

Fig. 8 Failure in sandstone block with horizontal joints, as the load is applied following failure pattern results starting from (a-e). a no loading is applied at this moment, $\mathbf{b}$ as the loading started small cracks is generated at the tunnel bottom, $\mathbf{c}, \mathbf{d}$ stepwise cracking is developed and complete failure of the block as it touches the ultimate load-bearing capacity of the rock block

crack generation and propagation at the tunnel sidewalls. The vertical joint block test was also repeated and can be seen in the following Fig. 10(a-d).

\section{b value and $\mathrm{lb}$ value comparison}

In this study, both $\mathrm{b}$ and Ib values were compared. The results showed that the shape of both plots were matching (Fig. 11). Since the Ib value is an improved and updated one, so the authors explained the $\mathrm{AE}$ results in terms of $\mathrm{Ib}$ value. 


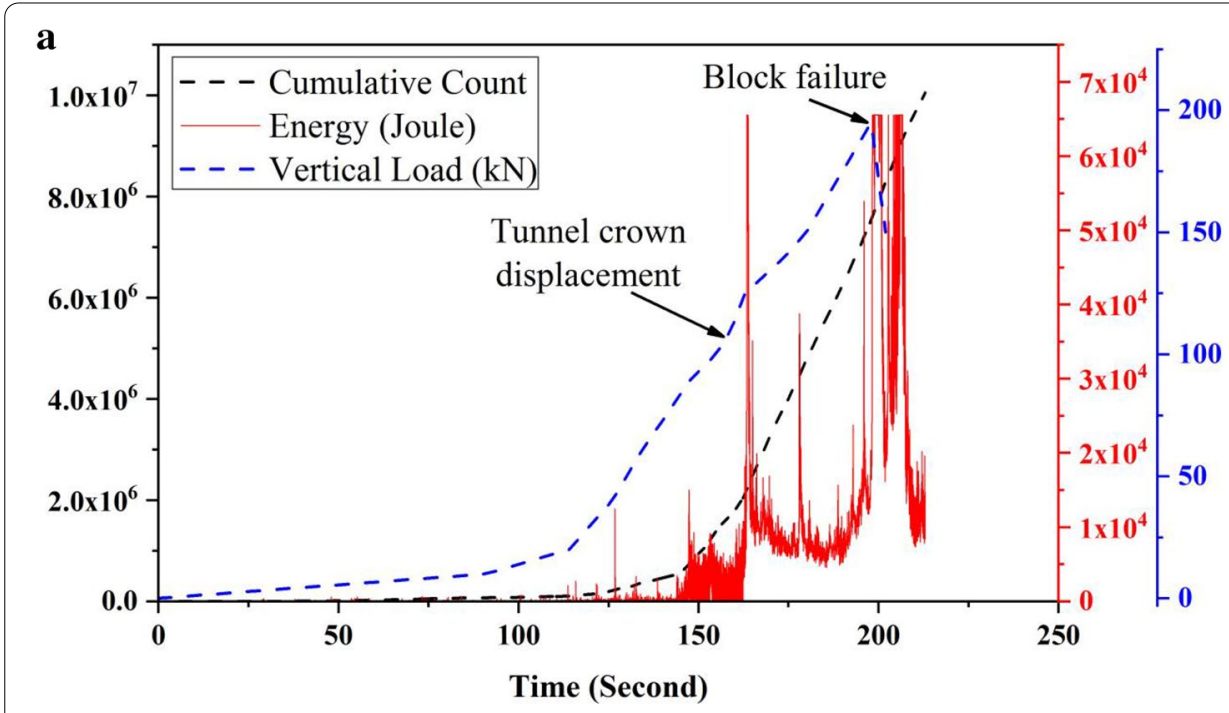

b

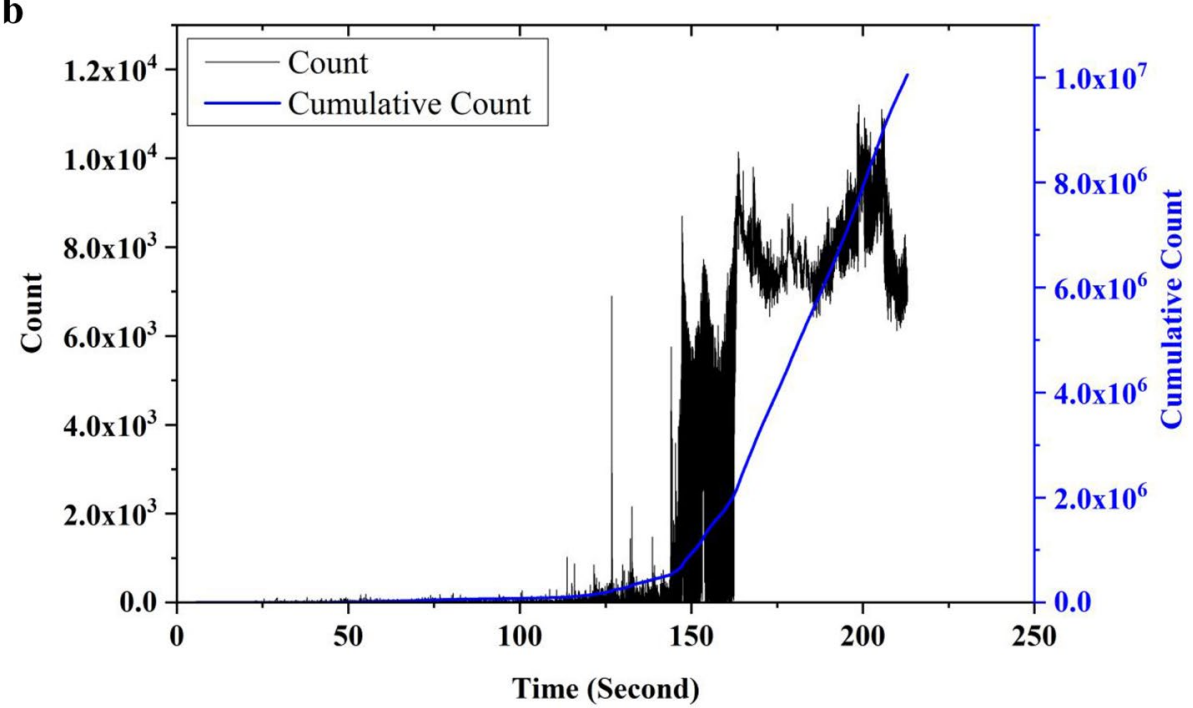

Fig. 9 Vertically layered block, a Plot showing the acoustic behavior and load vs time (b) Count and cumulative count vs Time

\section{Relationship of rock damage and Ib values}

During the experiment, the variation in the Ib-value indicates progressive cracking and damage process of the rock tunnel under uniaxial compression. The outcomes of the experiments show that, during the early stage of loading, a huge number of $\mathrm{AE}$ events were generated due to the closure and rubbing of the pre-existing microcracks which results in a high Ib-value. As the loading continued, the formation and propagation of newly formed cracks on the subsequent fracture surface produce a large amount of energy and AE hits, resulting in the high Ib-value. As the load approaches ultimate failure load, the Ib-value decreased sharply due to the crack coalescence and the accompanying stress relief under the further increased stress. 

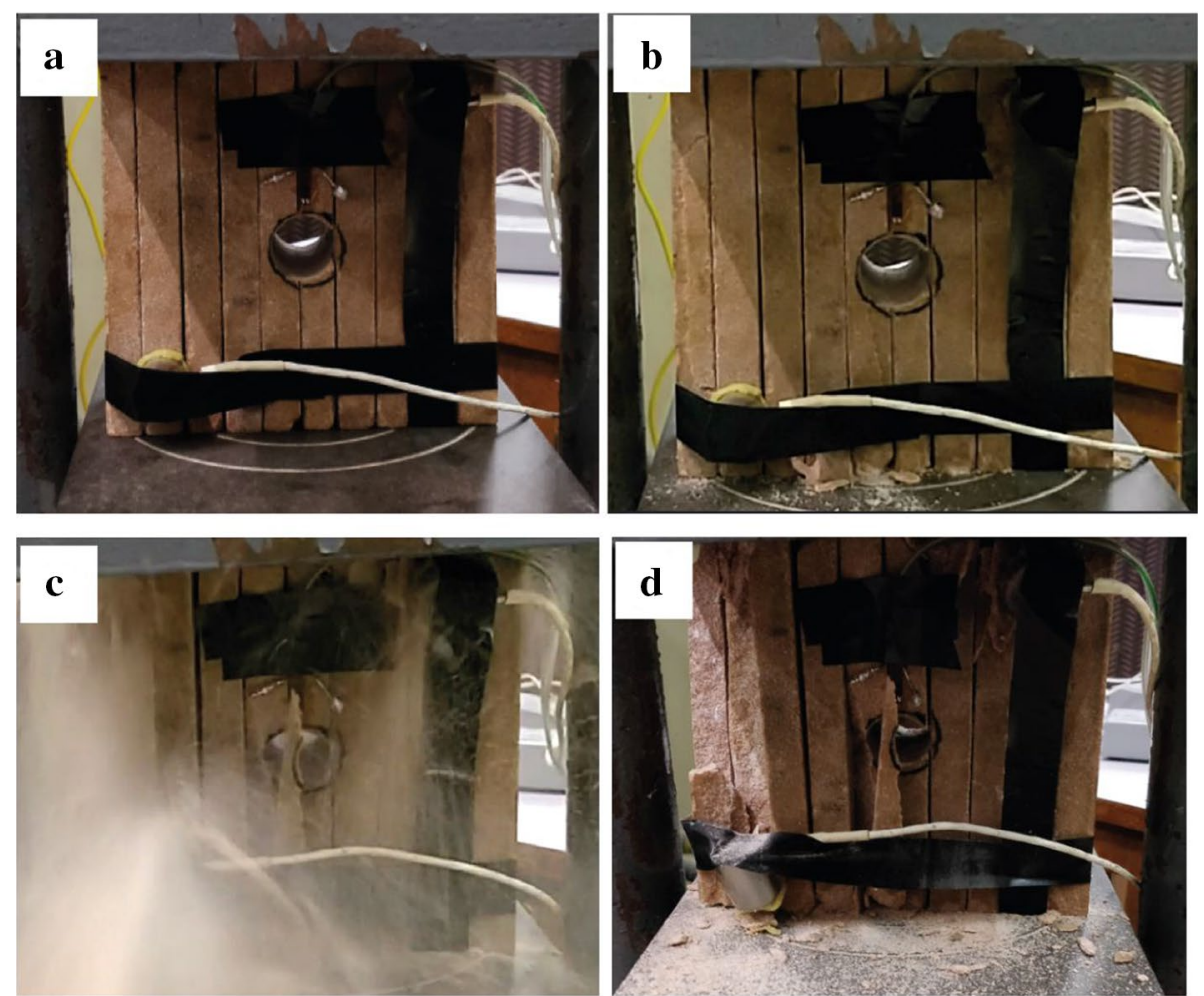

Fig. 10 Failure in sandstone block with vertical joints, as the load is applied following failure pattern results starting from (a-d). a pretest setup (no load is applied), $\mathbf{b}$ loading started, small crack is generated near the tunnel, $\mathbf{c}, \mathbf{d}$ failure at ultimate load

The critical time of this decreasing phenomenon of the Ib value can be considered as most useful for the prediction of rock failure time. There is an inverse relationship exist between the Ib value and the energy released by the sample during loading. In Fig. 12a, for the intact rock block, it is clear that at around $210 \mathrm{~s}$ there is a large energy release peak and the Ib value also very low before that zone. The sudden sharp decrease of Ib value is observed between 160 to 200 s (i.e. before the large energy release event).

As can be seen in Fig. 12a, the Ib-value in micro-crack nucleation stages shows an increasing trend from 100 to $150 \mathrm{~s}$, and thereafter a steady stage was observed between 150-175 s for the macro-cracks formation. A significant drop was recorded while macrocracks started to open from 175-200 s. However, a decreasing trend in Ib-value can be known as a serious damage alert. Similar reading is also recorded for the block with horizontal joint sets, in Fig. 12b, at around $275 \mathrm{~s}$ there was a major peak energy release event. The overall slope of Ib value curve also showing a negative curve between $225-275$ s, i.e. before the peak stress release. But this process is somewhat insignificant with vertical joint sets because in this case the existence of vertical joint acts as a barrier for the stress concentration, crack generation, and propagation at the tunnel sidewalls (see Fig. 12c).

This scenario is best developed in the intact rock cases and with horizontal joint set condition where there was a sudden sharp drop and then a quiet period in the Ib value is followed by a large stress release or energy release or rock bursting process 

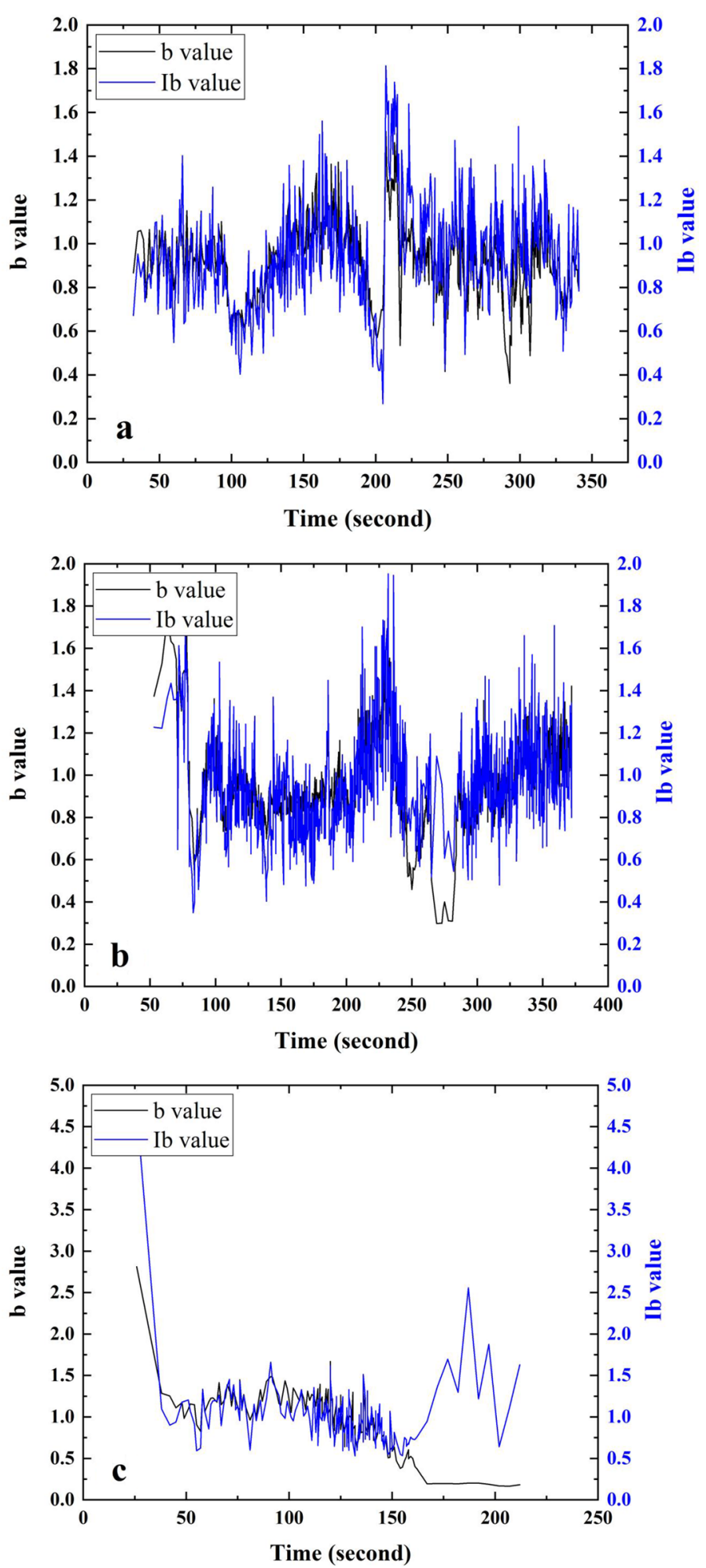

Fig. 11 The b-value (GBR) and Improved b-value (Ib) (PAC) were compared and plotted against experiment duration in all three cases i.e. (a) intact rock block (b) block with horizontal joint set and (c) block with vertical joint sets 
(See figure on next page.)

Fig. 12 Energy released values and $\mathrm{lb}$-value is plotted against time of the loading process up to failure in all three cases i.e. (a) Intact rock block (b) block with horizontal joint set and (c) block with vertical joint sets

(Fig. 12a, b). Since the rocks are opaque, hence it is difficult to monitor the internal deformation and failure process of rockmass. The Ib value determination using the $\mathrm{AE}$ technique appears to be the most useful monitoring practice in rock tunnels because it is an NDT. These observations have some important applications related to monitoring the stability and veracity of rock tunnels. The AE also helps scientists to the locate damage zones (with a considerable number of AE sensors) and their intensities with future rockburst predictions.

The Figs. 13, 14, demonstrates the cumulative count vs time and cumulative energy vs time (for all three cases), respectively. The energy loss in the jointed blocks can be identified from the plot. The intact rock block shows a higher cumulative count than the other two cases. The experiment results show that the intact rock block and rock block with the vertical joint set were stiffer against the loading, while the rock block with horizontal joint set shows minimum strength against vertical loading.

\section{Numerical modelling}

To provide detailed insight into the failure mechanism of surrounding rockmass around the underground opening in a jointed rockmass, a numerical tool based on the finite element method (FEM) is adopted to simulate the physical model problems and analyzing its stability. As mentioned by Nikadat et al. [5] the FEM is having fundamental steps i.e. domain discretization, local approximation, global matrix assembly, and solution. The problem domain is discretized into a finite number of subdomains called "finite elements" having a particular shape and fixed number of nodes [39].

In this study, a 2D FEM code "Phase2" is used to analyze stress distribution and total displacements around a circular tunnel in jointed rockmass. The material parameters used in the numerical model were those obtained from the laboratory experiments as described above. To model the rock, three-node triangular elements were used. Graded mesh type was used with a gradation factor of 0.1. Fixed restraints were applied to the bottom of the model, while the sidewall surface was left free to simulate exactly like the physical model experiment. In the numerical model, the tunnel model was loaded to the ultimate failure load of the physical model of the rock blocks. Uniform line load was applied at the top of the model viz. for the intact rock block, the magnitude of 39.22 MN/ $\mathrm{m}^{2}$ is applied. Similarly, for horizontal and vertical joint set blocks 11.67 MN/ $\mathrm{m}^{2}$ and $16.04 \mathrm{MN} / \mathrm{m}^{2}$ uniform line load was applied, respectively.

Based on the simulation results, the failure mode of the rock specimen can be categories into three categories:

Spalling-mode: High-stress concentration zone can be seen around the sidewalls of the tunnel (Fig. 15) which results in cut through cracks on both left and right side of the tunnel periphery causing violent ejection of rock pieces (for intact rock specimen).

Stepwise cracking pattern: The horizontal rock slices dominantly failed in layered beam mode. Here the cracks have a stepwise appearance. The newly formed cracks or fractures were ended abruptly at the joint planes (Fig. 16). 

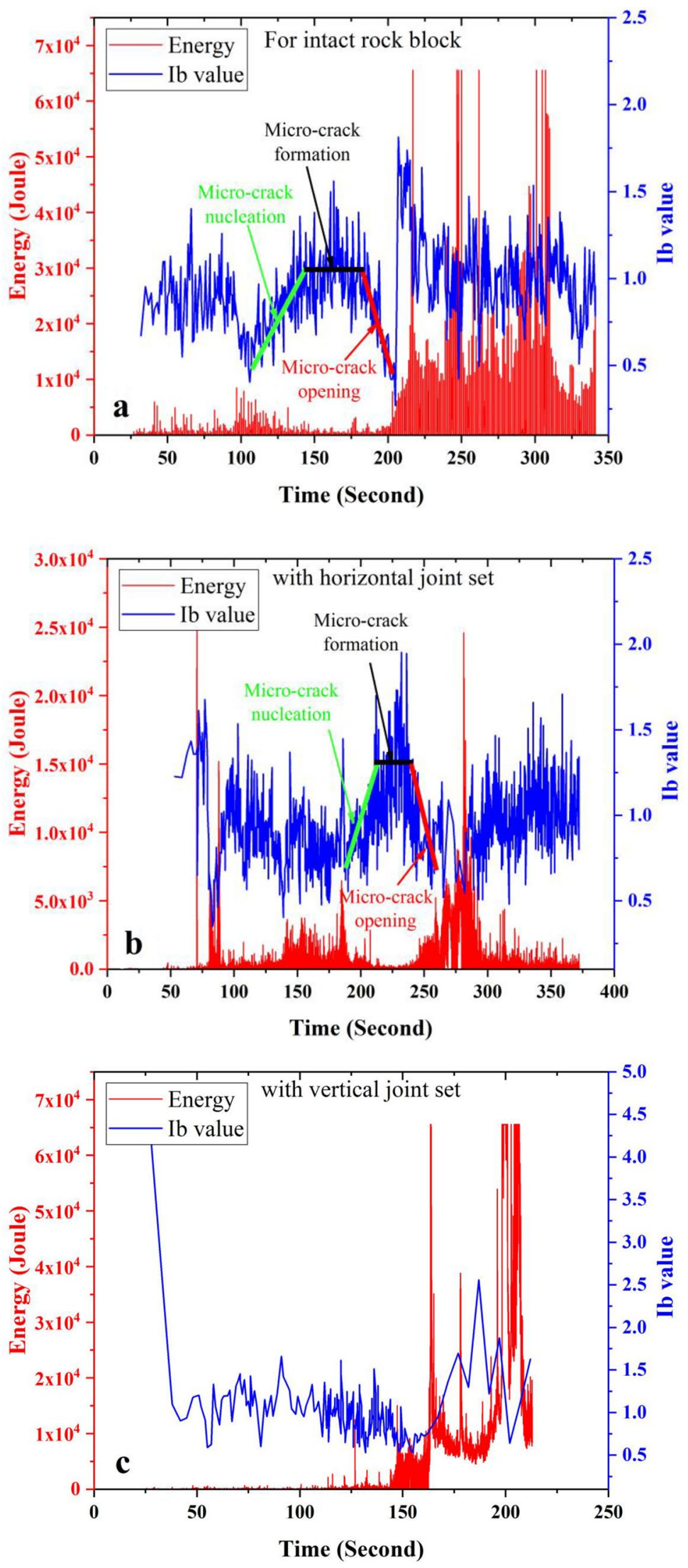


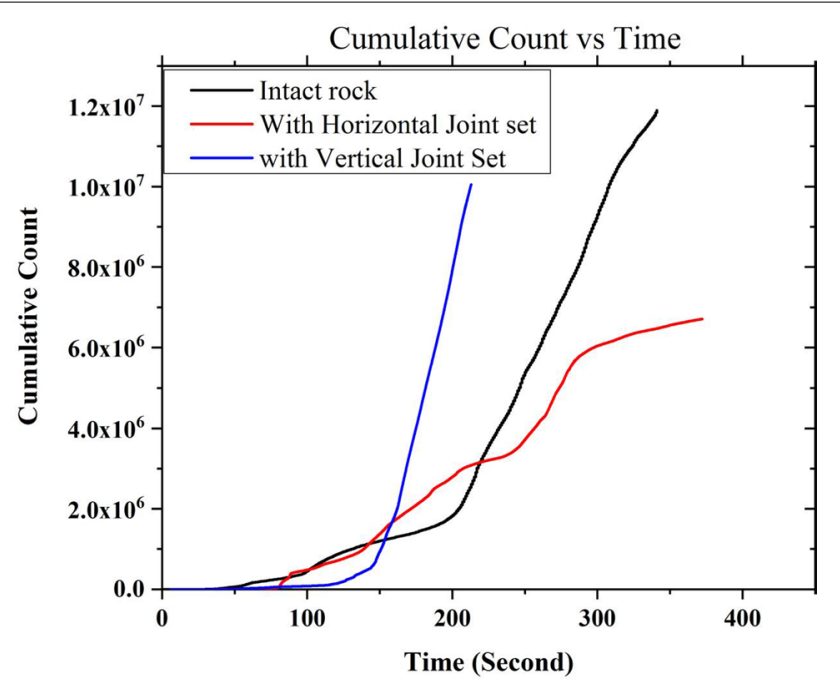

Fig. 13 Cumulative count vs Time

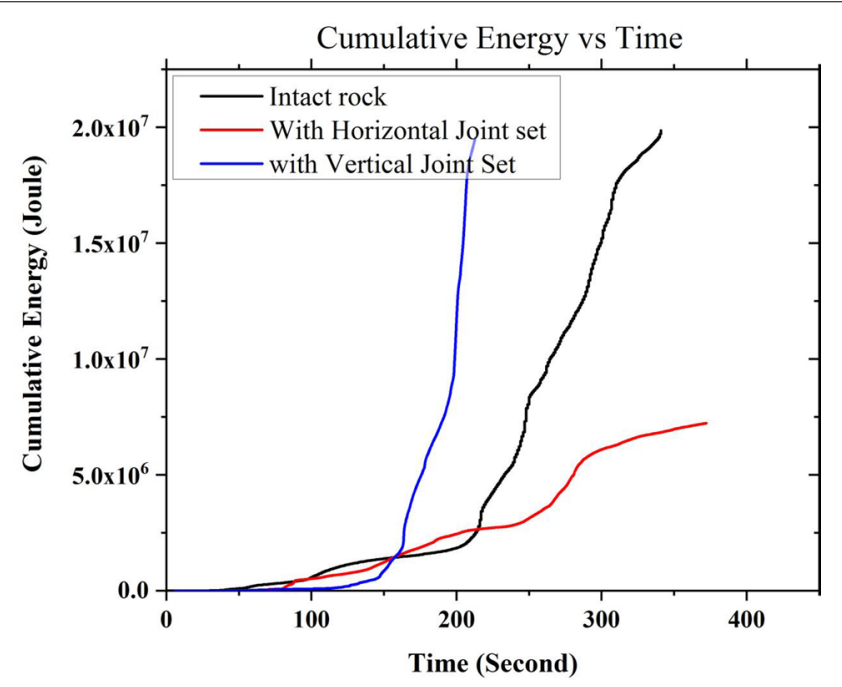

Fig. 14 Cumulative energy vs Time

Splitting-mode: Layer perpendicular joint extension is observed during the failure of the block with the vertical joint set. The joint open up perpendicular to the joint set due to resultant tension in the horizontal direction, which is a very common engineering phenomenon. As can be seen from the numerical results, the rock blocks above the tunnel are severely affected as compared to the blocks located far away from the tunnel (Fig. 17).

\section{Conclusion}

In this paper, a physical model test and 2D finite element numerical simulation were conducted for evaluating the adverse effect of jointed rockmass on its failure mechanism around an underground opening. The $\mathrm{AE}$ technique was used to monitor the 


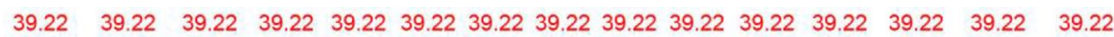

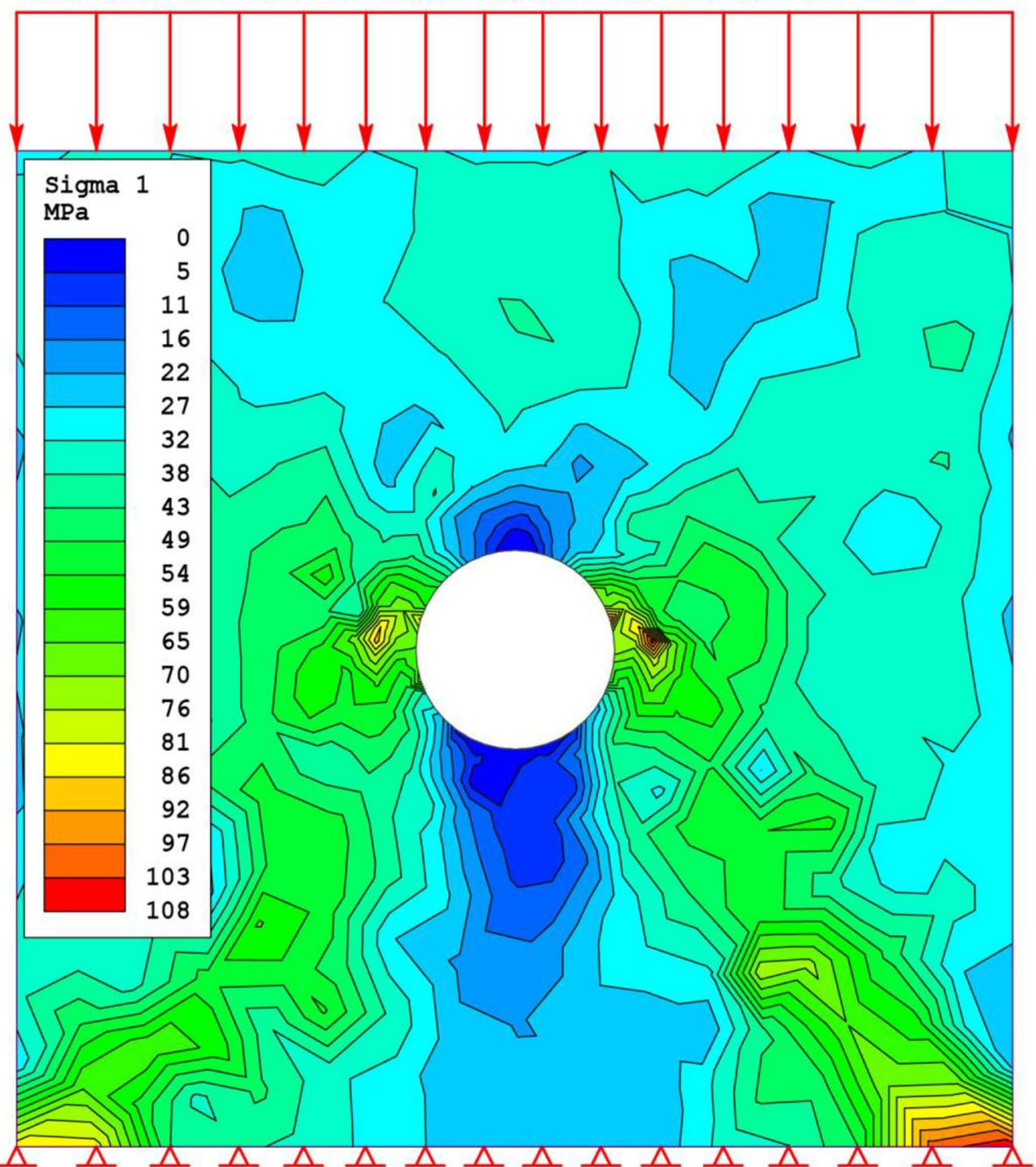

Fig. 15 Stress contour around the circular opening for the intact rock block

failure process of the rock tunnel subjected to vertical loading. The fracturing images and $\mathrm{AE}$ signals were simultaneously recorded. The $\mathrm{AE}$ results of the three cases (viz intact, horizontal joint set, and vertical joint set) has been carefully studied. The following conclusion can be drawn from the experimental data.

a. In the case of intact rock, the cracks generated during loading was continuous. The particle ejection phenomenon appeared within the hole and then developed into forceful ejection of sand particles from the sidewalls and exfoliation accompanied by the ringing sound of the burst. Cut-through cracks are clearly visible on both sides of the tunnel periphery after the violent ejection of rock pieces. The breakout is concentrated mainly at the sidewall portions due to higher stress concentration in that location.

b. In the Horizontal Joint condition, the horizontal joints have a significant effect on the crack formation and fracture pattern distribution. Here, the crack has a stepwise 


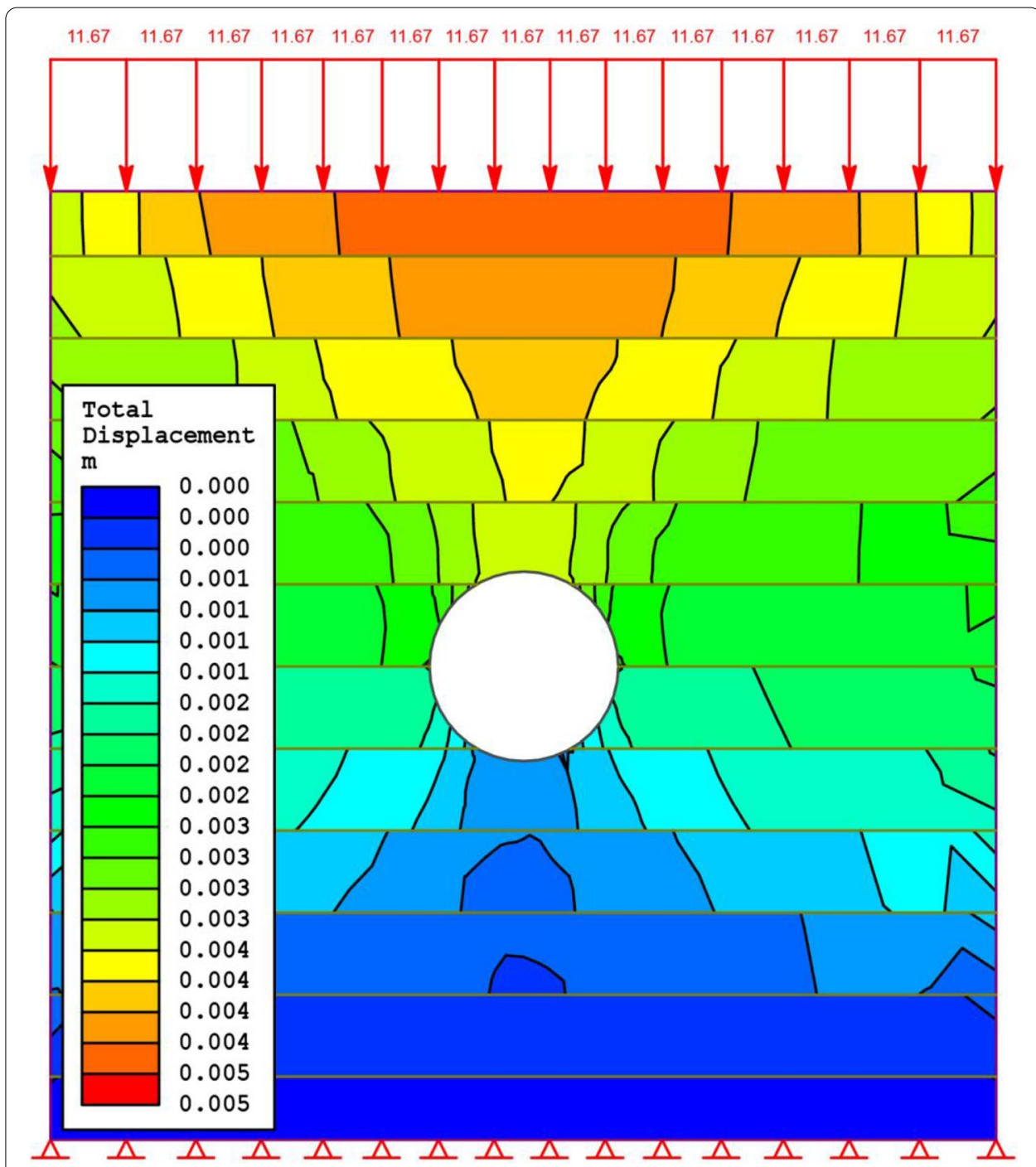

Fig. 16 Total deformation contour following a stepwise appearance in horizontally jointed block

appearance. Instead of spalling, a large shear crack is observed along the length of the hole.

c. In vertical joint condition, after loading, the vertical slices above the tunnel crown are moved into the tunnel which is solely supported by its own inherent joint shear strength. There was no sidewall deformation observed as it was in the case of intact rock condition. The presence of vertical joint acts as a barrier for the stress concentration, crack generation, and crack propagation at the tunnel sidewalls.

d. The presence of joints reduces the strength of the blocks significantly.

e. The AE cumulative counts are more in the case of the intact condition than the other two.

f. The Ib value was also computed to identify the micro and macro-structural cracks, generated in the sample. The AE events showed that a sudden drop and then a quiet 


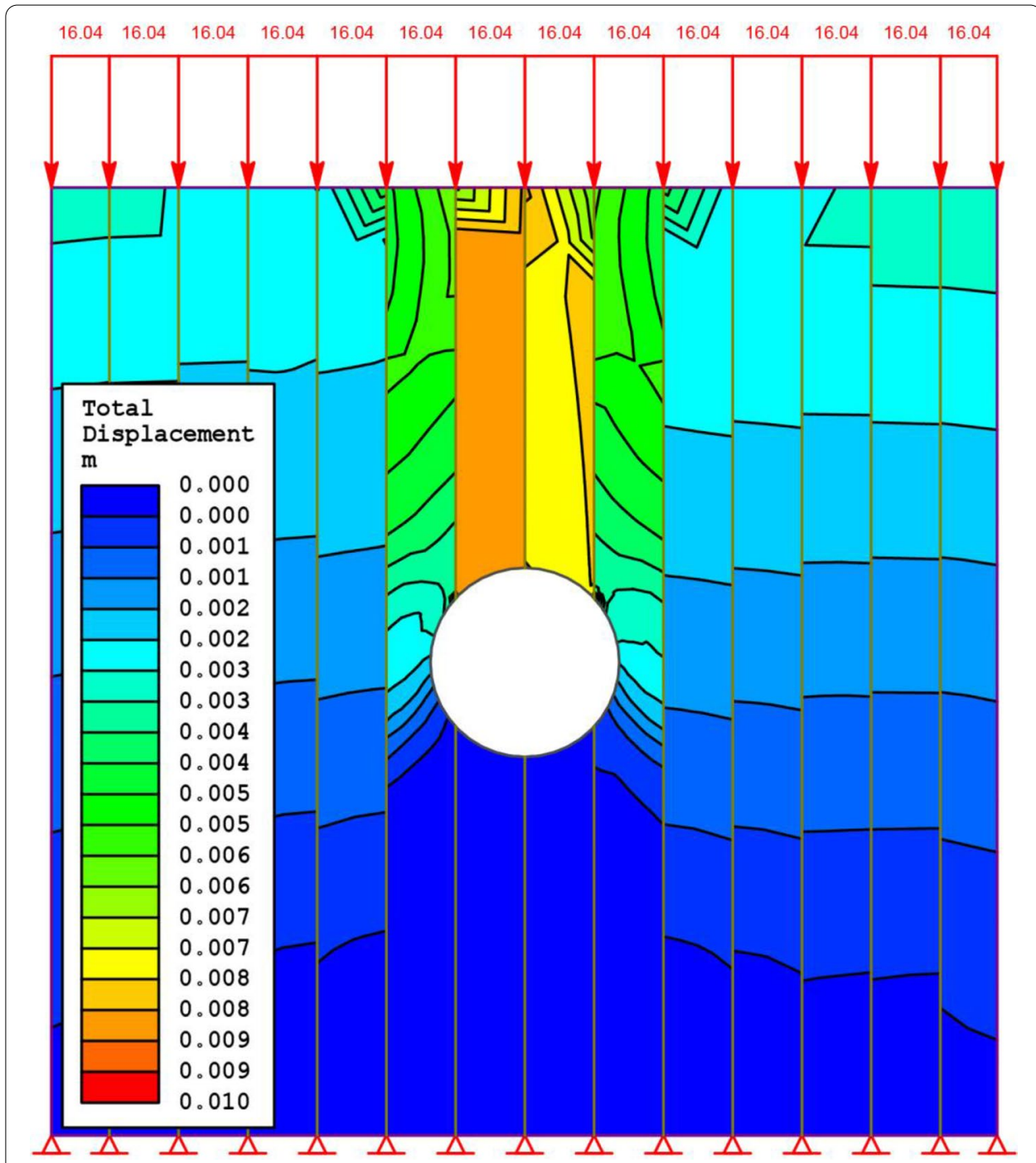

Fig. 17 Total displacement contour in vertically jointed block

period in the $I b$ values could be considered as the precursors to forecast the rockburst hazard.

g. The numerical simulation along with the $\mathrm{AE}$ in rock fractures can improve our understanding of the AE signals, before serious hazards and this will surely lead to better application of the AE technique for damage estimation.

\section{Acknowledgements}

The first author acknowledges the financial support from the Postdoctoral Fellowship Program of the Indian Institute of Technology Kharagpur. This research was conducted in Rock Science and Rock Engineering (RSRE) laboratory in the Department of Earth Sciences, Indian Institute of Technology Bombay.

\section{Declarations}

Competing interests

The authors declare that they have no competing interests. 


\begin{abstract}
Author details
1 Department of Geology \& Geophysics, Indian Institute of Technology Kharagpur, Kharagpur 721302, West Bengal, India.

2 Industrial Engineering and Operations Research, Indian Institute of Technology Bombay, Mumbai 400076, Maharashtra, India. ${ }^{3}$ Department of Earth Sciences, Indian Institute of Technology Bombay, Mumbai 400076, Maharashtra, India.
\end{abstract}

Received: 5 June 2020 Accepted: 1 December 2020

Published online: 10 May 2021

\title{
References
}

1. Huang L, Tang H, Tan Q, Wang D, Wang L, Ez Eldin MAM, Li C, Wu Q (2016) A novel method for correcting scanlineobservational bias of discontinuity orientation. Sci Rep 6:1-13. https://doi.org/10.1038/srep22942

2. Liang Z, Liu X, Zhang Y, Tang C (2013) Analysis of precursors prior to rock burst in granite tunnel using acoustic emission and far infrared monitoring. Math Probl Eng. 2013:1-10. https://doi.org/10.1155/2013/214340

3. Das R, Singh TN (2020) Effect of closely spaced, non-persistent ubiquitous joint on tunnel boundary deformation: a case study from Himachal Himalaya. Geotech Geol Eng. 39(3):2447-2459. https://doi.org/10.1007/ s10706-020-01637-3

4. Yang SQ, Yin PF, Zhang YC, Chen M, Zhou XP, Jing HW, Zhang QY (2019) Failure behavior and crack evolution mechanism of a non-persistent jointed rock mass containing a circular hole. Int J Rock Mech Min Sci 114:101-121. https:// doi.org/10.1016/j.jijmms.2018.12.017

5. Nikadat N, Fatehi Marji M, Rahmannejad R, Yarahmadi Bafghi A (2016) Effect of joint spacing and joint dip on the stress distribution around tunnels using different numerical methods. J African Earth Sci 123:193-209. https://doi. org/10.1016/j.jafrearsci.2016.07.025

6. Das R, Singh TN (2020) Effect of rock bolt support mechanism on tunnel deformation in jointed rockmass: a numerical approach. Undergr Sp. https://doi.org/10.1016/j.undsp.2020.06.001

7. Wang TT, Huang TH (2014) Anisotropic deformation of a circular tunnel excavated in a rock mass containing sets of ubiquitous joints: Theory analysis and numerical modeling. Rock Mech Rock Eng 47:643-657. https://doi.org/10. 1007/s00603-013-0405-8

8. Jia P, Tang CA (2008) Numerical study on failure mechanism of tunnel in jointed rock mass. Tunn Undergr Sp Technol 23:500-507. https://doi.org/10.1016/j.tust.2007.09.001

9. Moyo T, Stacey T (2012) Mechanisms of rockbolt support in jointed rock masses. In: Potvin Y (ed) Proc sixth int semin deep high stress min, pp 91-103. https://doi.org/10.36487/acg_rep/1201_06_moyo

10. Zhang ZX, Xu Y, Kulatilake PHSW, Huang X (2012) Physical model test and numerical analysis on the behavior of stratified rock masses during underground excavation. Int J Rock Mech Min Sci 49:134-147. https://doi.org/10. 1016/j.jijmms.2011.11.001

11. Madkour H (2012) Parametric analysis of tunnel behavior in jointed rock. Ain Shams Eng J 3:79-103. https://doi.org/ 10.1016/j.asej.2012.01.002

12. Sellers EJ, Klerck P (2000) Modelling of the effect of discontinuities on the extent of the fracture zone surrounding deep tunnels. Tunn Undergr Sp Technol 15:463-469. https://doi.org/10.1016/S0886-7798(01)00015-3

13. Xu NW, Tang CA, Li LC, Zhou Z, Sha C, Liang ZZ, Yang JY (2011) Microseismic monitoring and stability analysis of the left bank slope in Jinping first stage hydropower station in southwestern China. Int J Rock Mech Min Sci 48:950-963. https://doi.org/10.1016/j.jirmms.2011.06.009

14. Tang C, Wang J, Zhang J (2010) Preliminary engineering application of microseismic monitoring technique to rockburst prediction in tunneling of Jinping II project. J Rock Mech Geotech Eng 2:193-208. https://doi.org/10.3724/SP.J. 1235.2010 .00193

15. Ewy RT, Cook NGW (1990) Deformation and fracture around cylindrical openings in rock-I. Observations and analysis of deformations. Int J Rock Mech Min Sci 27:387-407. https://doi.org/10.1016/0148-9062(90)92713-O

16. Sirdesai NN, Singh TN, Pathegama Gamage R (2017) Thermal alterations in the poro-mechanical characteristic of an Indian sandstone-a comparative study. Eng Geol 226:208-220. https://doi.org/10.1016/j.enggeo.2017.06.010

17. Roy DG, Singh TN, Kodikara J (2017) Influence of joint anisotropy on the fracturing behavior of a sedimentary rock. Eng Geol 228:224-237. https://doi.org/10.1016/j.enggeo.2017.08.016

18. ASTM:D7012-14 (2014) Standard test methods for compressive strength and elastic moduli of intact rock core specimens under varying states of stress and temperatures. ASTM Int. https://doi.org/10.1520/D7012-14E01

19. ASTM:E132-04(10) (2011) Standard test method for poisson's ratio at room temperature. ASTM Int 04:2010-2012. https://doi.org/10.1520/E0132-04R10.2

20. Brown ET (1981) Rock characterization testing and monitoring: ISRM suggested methods for Determining Tensile Strength of Rock Materials. 119-121

21. Brown ET (1981) Rock characterization testing and monitoring: ISRM suggested methods for determining water content, porosity, density, absorption and related properties and swelling and slake-durability index properties. 81-89

22. Bandis SC, Lumsden AC, Barton NR (1983) Fundamentals of rock joint deformation. Int J Rock Mech Min Sci 20:249-268. https://doi.org/10.1016/0148-9062(83)90595-8

23. Goodman RE, Taylor RL, Brekke TL (1968) A model for the mechanics of jointed rock. J Soil Mech Found Div 94:637-659

24. Prudencio M, Van Sint JM (2007) Strength and failure modes of rock mass models with non-persistent joints. Int J Rock Mech Min Sci 44:890-902. https://doi.org/10.1016/j.jirmms.2007.01.005

25. Yang J, Liu C, Chen Q, Xie X (2017) Performance of overlapped shield tunneling through an integrated physical model tests, numerical simulations and real-time field monitoring. Undergr Sp 2:45-59. https://doi.org/10.1016/j. undsp.2017.04.002 
26. Hoek E, Carranza-Torres C, Corkum B, Diederichs MS, Corkum B (2008) The 2008 Kersten Lecture, Intergration of geotechnical and structural design in tunnelling. 56th Annu Geotech Eng Conf 54

27. Brown ET (1981) Rock characterization, testing and monitoring: ISRM suggested methods. Published for the commission on testing methods, international society for rock mechanics by pergamon press

28. Wang S, Huang R, Ni P, Gamage RP, Zhang M (2013) Fracture behavior of intact rock using acoustic emission: experimental observation and realistic modeling. Geotech Test J 36(6):903-914. https://doi.org/10.1520/GTJ20120086

29. Behnia A, Kian H, Shiotani T (2014) Advanced structural health monitoring of concrete structures with the aid of acoustic emission. Constr Build Mater 65:282-302. https://doi.org/10.1016/j.conbuildmat.2014.04.103

30. Shiotani T (2006) Evaluation of long-term stability for rock slope by means of acoustic emission technique. In: NDT and E International. pp 217-228

31. ASTM (2017) Standard Method for Primary Calibration of Acoustic Emission Sensors. ASTM Int, Des E1 106-12 (Reapproved 2017), West Conshohocken, PA 19428-2959 United States, 1:1-13. https://doi.org/https://doi.org/10. 1520/E1106-12R17

32. ASTM (2013) Standard practice for secondary calibration of acoustic emission sensors. ASTM Int, Des E1781/ E1781M-13, West Conshohocken, PA 19428-2959 United States, 1-7. https://doi.org/https://doi.org/10.1520/ E1781_E1781M-13

33. Md Nor N, Bunnori NM, Ibrahim A, Shahidan S, Basri SR, Saliah SNM (2012) B-value analysis of AE signal subjected to stepwise loading. In: Advanced Materials Research. Trans Tech Publications Ltd, pp 4126-4131

34. Gutenberg B, Richter CF (1954) Seismicity of the Earth and Associated Phenomena. Princeton University Press, Princeton

35. Kui Z, Zhicheng Z, Peng Z, Sanjian C (2015) Experimental study on acoustic emission characteristics of phyllite specimens under uniaxial compression. J Eng Sci Technol Rev 8:53-60. https://doi.org/10.25103/jestr.083.07

36. Smith WD (1981) The b-value as an earthquake precursor. Nature 289:136-139. https://doi.org/10.1038/289136a0

37. Colombo IS, Main IG, Forde MC (2003) Assessing damage of reinforced concrete beam using "b-value" analysis of acoustic emission signals. J Mater Civ Eng 15:280-286. https://doi.org/10.1061/(ASCE)0899-1561(2003)15:3(280)

38. Tian B, Liu S, Li J, Liang P, Zhang Y, Wang Z (2015) Experimental investigations into the effects of lithology on acoustic emission. J Eng Sci Technol Rev 8:210-216. https://doi.org/10.25103/jestr.083.28

39. Das R, Singh PK, Kainthola A, Panthee S, Singh TN (2017) Numerical analysis of surface subsidence in asymmetric parallel highway tunnels. J Rock Mech Geotech Eng 9:170-179. https://doi.org/10.1016/j.jrmge.2016.11.009

\section{Publisher's Note}

Springer Nature remains neutral with regard to jurisdictional claims in published maps and institutional affiliations. 